Revista lus et Praxis, Año 20, № 1, 2014, pp. 15 - 38

ISSN 0717 - 2877

Universidad de Talca - Facultad de Ciencias Jurídicas y Sociales

"Propósito práctico, incumplimiento contractual

y remedios del acreedor. Con ocasión de tres recientes sentencias de la Corte Suprema"

Íñigo de la Maza Gazmuri - Álvaro Vidal Olivares

Trabajo recibido el 25 de septiembre y aprobado el 2 de diciembre de 2013

\title{
Propósito práctico, incumplimiento contractual y remedios del acreedor. Con ocasión de tres recientes sentencias de la Corte Suprema
}

NON CONFORMITY, BREACH OF CONTRACT AND CREDITOR'S REMEDIES. In Light of SOME Recent Supreme Court DeCisions

\author{
Í̃̃igo de la Maza Gazmuri * \\ Álvaro Vidal Olivares ${ }^{* *}$
}

\begin{abstract}
REsUMEN
En las siguientes páginas nos ocupamos de presentar tres cuestiones centrales del derecho de contratos. La primera de ellas es la importancia del propósito práctico para determinar la fisonomía de la regla contractual. La segunda es una especie de incumplimiento -el cumplimiento imperfecto- y sus matices. En tercer lugar, nos ocupa considerar la articulación de los remedios del acreedor frente a tales incumplimientos. Para presentar estas cuestiones nos servimos de tres recientes sentencias de la Corte Suprema.
\end{abstract}

\section{ABSTRACT}

In the following lines we devote our attention to three key issues of contract law. First, the relevance of to determine the shape of the contractual rule. Second, we present a manifestation of breach of contract: non conformity and some of its details. Finally, we consider the way that remedies articulate around these kind of breach. We use three decisions recently issued by the Supreme Court to present these issues.

\section{PalABras CLAVE}

Contrato, Cumplimiento imperfecto, Efectos del incumplimiento

KEYWORDS

Contract, Partial breach, Effects of contract breach

\footnotetext{
* Profesor Investigador Facultad de Derecho de la Universidad Diego Portales; Profesor de Derecho Civil. Doctor en Derecho. Dirección postal: República 105, Santiago de Chile. Correo electrónico: inigo.delamaza@udp.cl. Este artículo se enmarca en el Proyecto Fondecyt regular No 1120548 . El tratamiento de las entregas defectuosas en el derecho chileno: hacia una noción de incumplimiento amplia y unitaria.

** Profesor Investigador Facultad de Derecho de la Pontificia Universidad Católica de Valparaíso; Profesor Titular de Derecho Civil. Doctor en Derecho. Dirección postal: Avenida Brasil 2950, Valparaíso. Correo electrónico: alvaro.vidal@ucv.cl. Este artículo se enmarca en el Proyecto Fondecyt regular No 1120708.
} 


\section{Introducción}

Tres recientes sentencias de la Corte Suprema se refieren de manera muy acertada a algunas de las cuestiones centrales en el derecho de contratos. La primera de ellas consiste en determinar la configuración del contenido del contrato (la regla contractual). La segunda cuestión se refiere a precisar qué desvíos de lo pactado en la ejecución de la prestación corresponden a cumplimientos imperfectos. La tercera, y última, está relacionada con los efectos de esta especie de incumplimientos y la protección del acreedor.

La Corte nos muestra, en primer lugar, la importancia del propósito que persiguen las partes y que protege el contrato, que se manifiesta tanto en la configuración de la regla contractual como en el alcance de la indemnización de perjuicios. Seguidamente, al examinar las tres sentencias, entendemos con mayor precisión el concepto de cumplimiento imperfecto, tan complejo y rico en consecuencias como, por lo general, ignorado por la doctrina nacional. En tercer lugar, la Corte Suprema enfatiza la autonomía de la pretensión indemnizatoria respecto de la acción resolutoria y la de cumplimiento forzado. Al mirar dos de las sentencias, comprendemos algunas de las sutilezas de esta autonomía.

El trabajo se divide en cuatro apartados. En el primero de ellos presentamos los hechos que originaron las sentencias y las preguntas que suscitan. En el segundo, nos ocupamos de la configuración de la regla contractual. El tercero refiere a la noción de cumplimiento imperfecto y la forma en que se manifiesta en estos tres casos. Y, el cuarto, y último, considera los efectos del incumplimiento desde dos ángulos: la presencia de concursos de acciones y la autonomía de la pretensión indemnizatoria.

\section{Los casos y las preguntas}

\subsection{Níquel, electricidad y representación judicial}

La primera sentencia es de 31 de octubre de $2012^{1}$ (en adelante nos referiremos indistintamente a ella como el caso de los "rodillos de laminación") y los hechos son los siguientes. Con fecha 10 de mayo de 2007, Zorin S.A. celebra contrato de compraventa con Compañía Siderúrgica Huachipato S.A., cuyo objeto corresponde a 1.500 toneladas de rodillos de laminación en desuso que debían contener una determinada composición química, particularmente una elevada cantidad de níquel. Convendrá aquí advertir que Zorin compró este material con la finalidad de venderlo a una empresa estadounidense. La Siderúrgica entregó, según lo convenido, una primera partida del material. Por su parte, Zorin procedió a enviar dicha partida a la empresa estadounidense. Empero, esta última compra-

1 Zorin S.A. con Compañía Siderúrgica Huachipato S.A. (2012). 
venta se frustró debido a que la empresa estadounidense detectó que el material enviado no contenía la concentración de níquel que se esperaba y que se había prometido. Según lo estima acreditado la Corte Suprema en su sentencia, dicha concentración era la misma convenida entre Zorin y la Siderúrgica.

Frente a estos hechos, Zorin demanda a la Siderúrgica con el objeto de que esta sea condenada a pagar una indemnización de los daños causados por la entrega de una cosa que tenía unas características distintas a las convenidas.

La segunda sentencia es de 16 de abril de $2013^{2}$ (nos referimos a ella, indistintamente, como la sentencia "del inmueble"). Se trata de un contrato de compraventa en el que el vendedor se obligó a construir y entregar un inmueble. En lo que aquí interesa, la cláusula primera del contrato, bajo el título OTROS, identificaba como una característica del inmueble que la "Electricidad será embutida con conduit PVC de $20 \mathrm{~mm}$ con 19 centros eléctricos". Por su parte, la cláusula segunda expresaba "Que por este acto 'el comprador' adquiere para sí el bien antes señalado, con todas las características antes especificadas". Más adelante, el mismo contrato prevé que la entrega tendría lugar siete semanas después de su firma. Sin embargo, transcurridas las siete semanas, la vendedora puso a disposición del comprador el inmueble sin instalaciones eléctricas y sin recepción definitiva.

El comprador demandó la resolución del contrato de compraventa y una indemnización de perjuicios, estimando como incumplida la obligación de entrega de la vendedora.

Finalmente, la tercera sentencia es de 28 de enero de $2013^{3}$ (la denominamos, indistintamente el caso de la "representación judicial"). Los hechos son los siguientes. Con fecha 22 de agosto de 2003, las partes suscribieron un contrato que denominaron Convenio de Honorarios, en virtud del cual, se encargó a un abogado la asesoría jurídica y defensa de un trabajador en la causa laboral correspondiente. Los honorarios se pactaron exclusivamente como de cuota litis, confiriéndose al abogado la facultad exclusiva de percibir las costas procesales y personales. Por otra parte, se estipuló que el trabajador no se obligaba a entregar ninguna suma de dinero al abogado para la tramitación del presente juicio. Los gastos serían de cargo del profesional. Se pactó, además, que se le cancelaría al abogado el 35\% de las prestaciones que se declarasen a favor del trabajador. A la demanda que presentó el abogado se sumaron cinco trabajadores más. El monto reclamado ascendió a $\$ 62.633 .855$, de los cuales $\$ 18.031 .698$, es decir el $28,78 \%$ de la cantidad, correspondían al trabajador que había celebrado el Convenio de Honorarios. Los otros cinco trabajadores no comparecieron a dicho

2 José Valdivia Lucero con Same Madrid y Madrid y Compañía Limitada (2013).

3 José Ampuero Asencio con Alfonso Castillo Hernández (2013). 
Convenio. El juicio concluyó con un avenimiento en el cual el empleador pagó $\$ 34.000 .000$. De esta suma, $\$ 4.000 .000$ correspondieron a costas. De los 30 millones restantes descontó sus honorarios y el excedente lo distribuyó entre los seis trabajadores, entregando 3 millones a cada uno.

El trabajador que había celebrado el convenio de honorarios, demandó al abogado la indemnización de perjuicios por el incumplimiento contractual en que había incurrido este último. Dicho incumplimiento consistía en que la suma entregada resultaba inferior a la que lo obligaba el convenio suscrito.

\subsection{Las preguntas}

Los hechos recién descritos y las pretensiones de los actores plantean tres preguntas que pueden formularse de la siguiente manera:

a. ¿A qué estaban contractualmente obligados los demandados? O planteado de forma más general ¿cómo se configura la regla contractual?

b. ¿De qué manera incumplieron los demandados el contrato? $\mathrm{O}$, si se quiere ¿en qué consiste un cumplimiento imperfecto?

c. ¿Qué efectos producen los eventuales incumplimientos? En otras palabras ¿Cómo protege la regla contractual al acreedor?

En las siguientes secciones de este trabajo procuraremos responder estas preguntas, principalmente, con cargo al razonamiento de la Corte Suprema en las sentencias recaídas en los hechos ya expuestos.

\section{La configuración de la regla contractual ¿Qué es lo debido?}

\subsection{Las reglas del pago}

¿Qué nos enseñan las sentencias sobre la configuración de la regla contractual? Podemos comenzar por la sentencia de los rodillos de laminación. Particularmente, por su considerando cuarto, del siguiente tenor:

"Que conforme con el artículo 1828 del Código Civil, el vendedor es obligado a entregar lo que reza el contrato, lo que supone un cumplimiento estricto a los términos del mismo, norma que debe complementarse con lo que disponen los artículos 1568 y 1569 del mismo Código. Estas disposiciones describen el pago efectivo como la prestación de lo que se debe, ordenan que el pago se hará 'bajo todos los respectos en conformidad al tenor de la obligación', salvo casos especiales contemplados por las leyes, y prescriben que 'el acreedor no podrá ser obligado a recibir otra cosa que lo que se le deba ni aun a pretexto de ser igual o mayor valor la ofrecida'".

En primer lugar, entonces, la Corte Suprema nos indica que la respuesta acerca de qué es lo debido debe encontrarse en las reglas del pago, ya sea en las generales -artículos 1568 y 1569 - o en aquellas particulares de la com- 
praventa respecto a la obligación de entrega -artículo 1828-. La prestación se debe según "lo que reza el contrato" o bien "al tenor de la obligación". Algo semejante puede desprenderse de la sentencia sobre representación judicial si se presta atención a sus considerandos 9 y 11 . Especialmente, cuando expresan que, según lo dispuesto en el artículo 2131, el mandatario se obliga a cumplir el encargo ciñéndose rigurosamente a los términos del mandato.

La respuesta de que nos provee la Corte Suprema es, desde luego, correcta. Sin embargo, en cierto sentido resulta insatisfactoria. Porque consideradas las cosas con cuidado, la Corte no ha terminado de responder nuestra pregunta, sino que la ha reformulado. Lo que ahora nos preocupa es qué hemos de entender por lo que "reza el contrato", el "tenor de la obligación" o "los términos del mandato".

\subsection{Buena fe y propósito práctico del contrato}

Esta segunda cuestión puede ser considerada a partir del considerando sexto de la sentencia sobre el inmueble que se entregó defectuosamente. En la parte que aquí interesa dispone:

"El artículo 1546 del Código Civil dispone que los contratos deben ejecutarse de buena fe, y por consiguiente obligan no solo a lo que en ellos se expresa, sino a todas las cosas que emanan de la naturaleza de la obligación, o que por la ley o la costumbre pertenecen a ella.

¿A qué se obligó Madrid y Madrid Compañía Limitada?

A lo que se expresó en la estipulación

A lo que emana de la naturaleza del contrato

A lo que por la ley o la costumbre pertenecen a esa"

En el mismo sentido, convendrá tener presente el considerando 11 de la sentencia sobre representación judicial, en el que se expresa que las partes únicamente acordaron sobre el objeto del encargo y sobre los honorarios que percibiría el abogado y no sobre la forma de distribuir los fondos que se obtuvieron. Sin embargo, la Corte estima que "naturalmente" corresponde una repartición a prorrata de sus derechos.

Lo que se saca en limpio de estos dos considerandos es que expresiones como lo que "reza el contrato", el "tenor de la obligación" o "los términos del mandato", no limitan la regla contractual a la literalidad del acuerdo. Para decirlo de otra manera, el deudor puede quedar -y generalmente será así- obligado más allá de lo expresado en el contrato.

De esta manera, cobra relevancia el principio de la buena fe, integrando al contrato contenidos sobre los cuales las partes no se pronunciaron explícita- 
mente pero que, sin embargo, contaron con ellos. Esta idea no es, desde luego, particularmente novedosa ${ }^{4}$, sin embargo, cuando miramos la forma en que la desarrollan las sentencias encontramos algo que sí puede resultar novedoso.

Intentemos ilustrar esta idea con las sentencias.

Tratándose de la sentencia del inmueble, el comprador consideró que se había incumplido con la obligación de entrega toda vez que éste carecía de instalaciones eléctricas y no había obtenido la recepción municipal.

Con respecto a la recepción municipal, aun cuando nada se decía en el contrato, la Corte integra su contenido acudiendo a la Ley General de Urbanismo y Construcciones, específicamente a su artículo 144. En principio, esta integración aparece como una aplicación casi trivial del artículo 1546 que, como se ha dicho, dispone que el contrato obliga a todas las cosas que por la ley le pertenecen. Sin embargo, cabría preguntarse por qué esa ley y no otra. ${ }^{5}$ La respuesta viene dada por la consideración que la Corte hace respecto del "propósito" de las partes. En palabras de la Corte (considerando 15):

"(...) Aquí se "vendió" una casa que el vendedor levantó en terreno del comprador Valdivia.

Por consiguiente, no merece dudas a estos juzgadores que la obligación que contrajo el vendedor no está cumplida por mientras no se entregue al comprador el inmueble como un todo, tal cual reza el contrato -especie o cuerpo cierto- en estado de ser utilizado para el propósito que ambas parte (sic) entendieron al consentir, es decir, de vivienda (...)"

La integración del citado artículo 144, que se traduce en la carga administrativa de regularización del inmueble, se explica a partir del propósito consistente en servir de vivienda para el comprador.

Algo similar sucede respecto de la electricidad en el caso del inmueble ¿Por qué la entrega de un inmueble sin instalaciones eléctricas debería constituir un incumplimiento que justifique la resolución del contrato? El propio Tribunal señala en el considerando 12 que, no obstante el hecho de que la electricidad no sea algo de la esencia de un inmueble, atendiendo al propósito de las partes -esto es destinarlo a vivienda- sí lo es en este inmueble. Una vez más, la explicación ha de encontrarse en el propósito de las partes.

\footnotetext{
4 Fue tempranamente advertida entre nosotros por FuEYO (1958).

5 Por ejemplo en el caso de la sentencia de la Corte Suprema de 27 de julio de 2005. El Tribunal, considerando la finalidad del comprador integra el contrato de compraventa aplicando las normas del Reglamento Sanitario de Alimentos contenido en el Decreto № 977/96 (Diario Oficial 13.05.97. Cecinas La Preferida S.A. con sociedad Comercial Salinak Limitada (2006). Con comentario en Revista Chilena de Derecho Privado, № 6, 2006, pp. 155-162.
} 
La idea de "propósito" a que nos ha llevado el examen de la integración a través de la buena $\mathrm{fe}^{6}$ se manifiesta también -aunque esta vez implícitamente-en el caso de los rodillos de laminación. Y aquello se aprecia desde dos ángulos. Primero, al definir si ha habido o no incumplimiento y, segundo, al precisar el alcance de la indemnización.

Comencemos por la definición de incumplimiento.

Se trata del considerando primero, según el cual, el incumplimiento contractual se produjo porque la cosa entregada carecía de una característica que se había convenido (la concentración de níquel). La importancia de esta carencia se explica, precisamente, por el propósito del comprador, asegurado por el contrato. Ese propósito, según nos muestra el considerando tercero de la sentencia, consistía en revender los rodillos. Al carecer de la concentración de níquel convenida, dicho propósito se vio frustrado. La consideración de tal propósito, con el que el vendedor naturalmente debía contar, permite al Tribunal concluir que el vendedor entregó una cosa distinta a la debida, lo que, en definitiva, repercute-como diremos inmediatamente- en la extensión de la indemnización del lucro cesante.

En lo que respecta a la indemnización, de no tener en cuenta el Tribunal la finalidad o propósito del comprador, no habría podido resolver acerca de la procedencia de la indemnización del lucro cesante. En efecto, la sentencia, en su considerando décimo octavo, se sirve de este propósito o finalidad para aplicar el criterio de la previsibilidad que permite incluir a la indemnización esta partida de daños. Se lee en el mencionado considerando:

“(...) La frustración de un negocio de esta naturaleza parecía perfectamente previsible, al tiempo de celebrar el contrato, para los efectos del artículo 1558 del Código Civil, pues, era natural que la empresa compradora quisiera revender el material de chatarra que estaba adquiriendo. (...)".

El Tribunal da lugar a la indemnización del lucro cesante como debido en "cumplimiento del contrato" (considerando décimo) en razón de ser previsible para el vendedor al tiempo de su celebración en atención al natural propósito de reventa del comprador.

Pues bien, en los párrafos anteriores se ha mostrado cómo explícitamente-en la sentencia del inmueble- e implícitamente -en la sentencia de los rodillos de laminación-, la Corte Suprema se sirve de la idea de "propósito" de las partes, ya sea para precisar el contorno de la obligación, o bien para determinar el incumplimiento o el alcance de la indemnización de daños y perjuicios.

\footnotetext{
6 La vinculación entre buena fe y propósito práctico ya había sido advertida en BARAONA (1998), pp. 78-79 y ALCALDE (2008), pp. 72-73.
} 
Esta importante idea de "propósito" que instala la Corte en sus sentencias se entronca directamente con uno de los aportes más inspiradores de la doctrina civil española en materia de derecho contractual: la noción de "propósito práctico" del contrato, acuñada por Federico de Castro y Bravo, y cuya presentación más precisa se encuentra en un trabajo de Antonio Manuel Morales Moreno. ${ }^{7}$ En palabras de este último autor:

El negocio jurídico debe ser entendido, siguiendo la idea de Castro, no simplemente como un mecanismo de creación, modificación o extinción de relaciones jurídicas, aunque también le cabe ese cometido, sino como algo más complejo y de más amplio alcance: como un medio para organizar los particulares sus propios intereses. Extrayendo las consecuencias que pueden derivarse de este enfoque, resulta que todo negocio, en sí mismo considerado, justifica en quienes lo han celebrado un determinado interés, que razonablemente aspiran a ver satisfecho y que también, por múltiples causas, unas imputables a la conducta de la otra parte y otras no imputables a ella puede quedar sin satisfacción. ${ }^{8}$

En definitiva, para Castro, el "propósito práctico" es el resultado que las partes buscan y que se va a conseguir a través del cumplimiento del negocio. Volvamos, por un momento, al texto del profesor Morales Moreno:

Según Castro, "se tiene en cuenta mejor la verdadera voluntad de los particulares atendiendo al fin práctico del negocio". Y para ilustrarnos lo que esto significa nos ofrece un ejemplo muy esclarecedor. Atendiendo a un punto de vista para él criticable, en la compra de una casa, "quedaría extramuros del derecho el propósito práctico del comprador de habitarla o arrendarla, aunque de ello se tratara con el vendedor". En cambio, -en su opinión-conforme al fin práctico propuesto (como hacen en sus decisiones los tribunales), se entenderá integrado en el propósito negocial el habitar o arrendar la casa, y consiguientemente quedará viciado el negocio cuando se oculta el mandato de su derribo (por ejemplo, por servidumbre hacia un aeródromo por ser zona militar) o la prohibición de arrendar (por ejemplo, respecto a ciertas construcciones protegidas)" ${ }^{9}$

Ahora bien, convendrá advertir que la noción de "propósito práctico" del contrato no se confunde -ni debe confundirse- con los motivos personales de

\footnotetext{
7 Morales (1983), pp. 1529-1546.

8 Morales (1983), p. 1531.

9 Morales (1983), p. 1534.
} 
las partes. Para que dichos motivos configuren el propósito práctico del contrato es necesario que, de alguna manera, se incorporen a él.

Excede las pretensiones de este trabajo precisar detalladamente cómo tiene lugar tal incorporación. En definitiva, se trata de un problema de interpretación contractual. Sin embargo, de la lectura de las sentencias aparece que tal incorporación no requiere de una declaración de voluntad expresa ${ }^{10}$, sino que puede derivarse de las circunstancias que rodearon la celebración del contrato.

Así, por ejemplo, en el caso del inmueble, la ubicación en la que se construyó la vivienda fue determinante para advertir que el propósito práctico del contrato exigía que la casa sirviera para la finalidad de habitación. Y en el caso de los rodillos de laminación, del hecho que se esté negociando entre comerciantes aparece como natural e indiscutible que los rodillos cumplieran con una cierta concentración de níquel para poder ser revendidos.

Antes de concluir con este apartado, nos interesa enfatizar, una vez más, la importancia del propósito práctico en estas dos sentencias de la Corte Suprema. Sin acudir -explícita o implícitamente- a esta idea, el Tribunal no habría tenido elementos suficientes para decidir sobre las controversias en torno al incumplimiento y sus consecuencias. En efecto, tratándose de los rodillos de laminación, la única forma de justificar la entrega de una cosa distinta a la debida y la procedencia del lucro cesante es a través de la consideración de la finalidad natural de revender la cosa. Por otra parte, en el caso de la entrega defectuosa del inmueble, el Tribunal construye el fundamento de la resolución, precisamente, teniendo en cuenta el impacto que produce el cumplimiento imperfecto del vendedor en el propósito convenido por las partes.

\section{El incumplimiento del contrato (cumplimientos imperfectos)}

\subsection{La idea de cumplimiento imperfecto}

Los incumplimientos a que refieren estas tres sentencias se caracterizan porque la prestación debida se ejecutó. Sin embargo, no se ejecutó según lo previsto en el contrato, sino de una forma diversa. Así, para ilustrar la cuestión, puede recurrirse a la sentencia recaída sobre los rodillos de laminación. Particularmente, a su considerando octavo. En los siguientes términos:

"Esta Corte entiende que, en una compraventa de estas características, el hecho de que la cosa no reúna las características o cualidades ofrecidas -no

\footnotetext{
${ }^{10}$ En otro caso, la Corte se ocupó de un conflicto en el que el propósito práctico había sido incorporado expresamente. Se trata de Glide Diversiones Limitada con Compañía de Inversiones y Desarrollo Sur S.A, (2008). En ese caso se arrendó un predio con la expresa finalidad de dedicarlo a un campo de minigolf, cuestión que, en definitiva, no se logró por las limitaciones urbanísticas que afectaban al predio.
} 
apareciendo que se trata de una cosa comprada a la vista, de acuerdo con los artículos 133 y 134 del Código de Comercio- configura un incumplimiento del vendedor, quien no ha cumplido cabalmente con la obligación de entrega, conforme con los artículos 1828, 1568 y 1569 del Código Civil. La cosa que ha entregado el vendedor es distinta a la comprada, lo que permite calificar a este hecho de un cumplimiento imperfecto, conforme con el artículo 1556 del Código Civil. Esta doctrina ha sido reconocida por la sentencia de esta misma Sala, Rol 5320-03".

Se trata, en el lenguaje de la Corte, de cumplimientos imperfectos. ${ }^{11}$ Esta misma idea ya había sido utilizada por la Corte Suprema en su conocida sentencia de 27 de julio de $2005^{12}$, particularmente en su considerando cuarto.

"Que, habiendo sido recibida la cosa comprada, se ha producido lo que la doctrina llama el cumplimiento imperfecto, porque el vendedor cumplió su obligación de entregar sin reclamo de parte del comprador, pero en definitiva, como se ha señalado, el producto resultó ser otro diferente al comprado".

La noción de cumplimiento imperfecto engloba una serie de desviaciones de la prestación ejecutada respecto de la prestación convenida. Resultará útil, en primer lugar, precisarlas y luego, advertir qué tipo de cumplimiento imperfecto ha originado estas tres sentencias. Una extensa cita de Díez-Picazo nos colaborará en esta tarea.

"En términos generales, existe cumplimiento inexacto o defectuoso de la obligación siempre que el comportamiento solutorio llevado a cabo por el deudor no se ajuste a los presupuestos que aquel pago reclama para producir plenos efectos liberatorios y satisfactivos"13

De manera que, continúa este autor, los tipos de inexactitud pueden ser los siguientes:

"1. ${ }^{\circ}$ La inexactitud relativa a los sujetos del acto de cumplimiento (...)

$2 .^{\circ}$ La inexactitud que se refiere al objeto de la prestación, cuando se produce una contravención de los requisitos de identidad e integridad del pago.

$3 .^{\circ}$ La inexactitud relativa al lugar de la prestación, que se produce cuando el deudor cumple o pretende cumplir en un lugar diferente del señalado en la obligación.

11 Sobre la idea de cumplimientos imperfectos puede consultarse DE LA MAZA (2012).

${ }^{12}$ Cecinas La Preferida S.A. con sociedad Comercial Salinak Limitada (2006). Con comentario en Revista Chilena de Derecho Privado, № 6, 2006, pp. 155-162.

13 Díez-Picazo (2008), p. 699. 
4. ${ }^{\circ}$ La inexactitud relativa al tiempo de la prestación, que se reconduce a los supuestos de cumplimiento anticipado y de cumplimiento retrasado"14

Y concluye señalando:

"De todos los casos antes enumerados que se pueden englobar bajo la amplia rúbrica de cumplimiento inexacto de la obligación solo el señalado en segundo lugar requiere un tratamiento especial, pues todos los demás casos encuentran su solución, entre nosotros, dentro de la normativa del pago.

Por eso, el cumplimiento inexacto se puede calificar como «ejecución de una prestación defectuosa». La diferencia más importante que esta figura ofrece, frente al incumplimiento definitivo y a la mora es que, así como en estos últimos casos se ha producido una omisión total de prestación, en el nuestro existe un comportamiento positivo del deudor dirigido a cumplir, que, sin embargo, no se ajusta a los términos del programa establecido en el acto de constitución de la relación obligatoria. Dicho más claramente, no es que el deudor no haya hecho nada, sino que lo que ha hecho está mal hecho". ${ }^{15}$

\subsection{Anomalías cualitativas y cuantitativas}

Los cumplimientos imperfectos que nos interesan aquí son aquellos en que la desviación se encuentra referida al objeto de la prestación. En dos de los casos -el de los rodillos de laminación y el del inmueble sin electricidad-el defecto en el cumplimiento se explica porque la cosa carece de una cualidad determinante para la consecución del propósito del contrato. En el tercer caso -el de la representación judicial- la inexactitud ya no concierne a una calidad de la cosa entregada -el dinero-, sino a su cantidad. Por lo tanto, en los dos primeros casos, nos encontramos frente a anomalías cualitativas del objeto, y en el tercero, frente a una cuantitativa.

Los cumplimientos imperfectos resultan particularmente interesantes, de una parte, por su frecuencia e importancia práctica y, de otra, por el escaso interés que, en general, les ha prestado la doctrina. ${ }^{16}$

En general, y no obstante la amplia tipología de incumplimiento prevista por los artículos 1556, 1558 y 1489 del CC., comprensiva de cualquier desviación del programa de prestación (no prestación, prestación tardía y prestación defectuosa o imperfecta) dos han sido los supuestos que han ocupado a la doctrina: la falta de cumplimiento por imposibilidad, sea o no imputable al deudor, y el

\footnotetext{
${ }^{14}$ Díez-Picazo (2008), pp. 699-700.

${ }^{15}$ Díez-Picazo (2008), p. 700.

16 Ver, sin embargo, de LA MAZA (2012).
} 
cumplimiento retardado. El cumplimiento imperfecto o defectuoso pasa prácticamente inadvertido. ${ }^{17}$

Y este es parte del interés que tienen estas sentencias: en ellas el cumplimiento imperfecto se percibe con toda claridad, tanto en lo que se refiere a la ejecución (cumplimiento) como a su carácter defectuoso (imperfecto).

Comencemos por la ejecución. En los tres casos se procedió a la entrega. Tratándose del caso de los rodillos de laminación se entregó la primera partida de un total de 1.500 toneladas. Por lo que toca al caso del inmueble sin electricidad, el considerando primero de la sentencia señala que el demandante había reconocido el hecho de la entrega del inmueble. Finalmente, en el caso de la representación judicial, se entregó la suma de tres millones de pesos al demandante.

En todos los casos, la defensa -o parte de la defensa- de los demandados consistió en afirmar que habían cumplido con su obligación. Así, por ejemplo, en el caso de los rodillos de laminación, parte de la defensa consistió en afirmar que ellos habían sido entregados tal cual se habían ofertado, por lo que no había existido incumplimiento. Por su parte, en el caso del inmueble, la Corte de Apelaciones de Rancagua acogió la defensa del demandado consistente en que se había entregado el inmueble. Finalmente, tratándose de la representación judicial, el abogado demandado contestó la demanda solicitando su rechazo alegando el cumplimiento de su encargo al haber repartido por partes iguales la suma recibida en virtud del avenimiento celebrado. ${ }^{18}$

Procede, entonces, plantearnos la siguiente interrogante: ¿Por qué las entregas fueron defectuosas? ( $y$, por lo tanto, los cumplimientos imperfectos).

En el caso de los rodillos de laminación, éstos no reunían las características convenidas por las partes al no cumplir con la concentración de níquel pactada, no siendo idóneas para el propósito práctico asegurado por el contrato, esto es, su reventa. En el de la electricidad, si bien existió entrega material, la cosa carecía de dos calidades esenciales para su destino de servir de vivienda, a saber, instalación eléctrica y recepción municipal. En el tercero de los casos -el de la representación judicial-, no obstante el abogado haber entregado al demandante la suma de \$3.000.000 al demandante, ella era inferior a la que resultaba obligado conforme el contrato, que ordenaba una repartición de acuerdo a los años de servicio de los trabajadores.

\footnotetext{
17 VIDAL (2010), p. 146.

${ }^{18}$ Así, en el considerando 9 de la sentencia se lee:

El demandado, contrariamente, pretende excepcionarse de los montos reclamados, alegando haber cumplido íntegramente con sus obligaciones, desde que al no existir en forma previa un pacto entre los demandantes del proceso laboral en orden a dar una distribución distinta a los fondos obtenidos, procedió con acuerdo de los mismos, a repartir el importe en partes iguales.
} 
De este modo, en los tres casos el Tribunal tiene por configurado el incumplimiento al constatar que, no obstante la actividad del deudor, ésta no se ajustó bajo todos los respectos conforme a la regla contractual (artículo 1569 CC).

Debemos precisar, en todo caso, que en los dos primeros casos y, también, en aquél de $2006^{19}$, la Corte pareciere identificar al cumplimiento imperfecto con la entrega de una cosa distinta a la debida. Esta asimilación requiere de alguna explicación.

Desde luego, si el deudor realiza una prestación que carece de la aptitud para la realización del propósito contractual y, consiguientemente, obsta a la satisfacción del interés del acreedor, se aplica el criterio judicial en orden a que el acreedor, conforme el artículo 1569 del CC, no estaría obligado a recibirla por ser "una cosa distinta" de la debida. Sin embargo, la noción de cumplimiento imperfecto no se limita a este supuesto. Se extiende, además, a todas aquellas hipótesis en las que la actividad del deudor no se conforma al contrato, independientemente de su idoneidad o no para la realización del propósito de las partes. Lo que queremos decir es que, si leemos con cuidado las disposiciones del pago, habrá casos en los que habiendo inexactitud en la prestación, el acreedor estará obligado a recibirla y conservarla, no obstante su derecho a exigir una indemnización por el deudor o su corrección. Es el artículo 1590 del CC el que nos permite llegar a esta conclusión. En efecto, la situación del acreedor es distinta según el deterioro -entiéndase defecto- sea o no de importancia. ${ }^{20}$

En fin, antes de dejar esta sección -y casi como una bisagra con la siguiente- nos interesa plantear una última cuestión. Se refiere a las dos compraventas, la de los rodillos de laminación y el inmueble. En ambos casos, resulta especialmente interesante plantearse cuál es la obligación que se considera incumplida. Y, tratándose de la compraventa regulada en el Título XXIII del Libro IV del Código Civil, o bien será la obligación de entrega o la de saneamiento. En ambos casos, la Corte Suprema entiende incumplida la obligación de entrega. Así se desprende, con toda nitidez, tratándose de la sentencia de los rodillos de laminación, del considerando octavo, que nos señala lo siguiente:

Que en consecuencia, debe dilucidarse si efectivamente esta circunstancia planea un caso de incumplimiento contractual que daría derecho a la compradora a ser indemnizada. Para resolver esta cuestión, es preciso determinar si la obligación de entrega que el comprador asume, en virtud del contrato de compraventa se satisface con la mera entrega física de la cosa comprada, que en este caso no hay duda de que efectivamente ocurrió,

${ }^{19}$ Cecinas La Preferida S.A. con sociedad Comercial Salinak Limitada (2006).

${ }^{20}$ Ver VIDAL (2010), p. 163. 
pues, las partes no han discrepado sobre este hecho, o por el contrario es imprescindible que el bien entregado reúna las calidades que se habían ofrecido y que las partes habían convenido. Sobre este punto, esta Corte entiende que, en una compraventa de estas características, el hecho de que la cosa no reúna las características o cualidades ofrecidas - no apareciendo que se trata de una cosa comprada a la vista, de acuerdo con los artículos 133 y 134 del Código de Comercio- configura un incumplimiento del vendedor, quien no ha cumplido cabalmente con la obligación de entrega, conforme con los artículos 1828, 1568 y 1569 del Código Civil. La cosa que ha entregado el vendedor es distinta a la comprada, lo que permite calificar a este hecho de un cumplimiento imperfecto, conforme con el artículo 1556 del Código Civil.

En el mismo sentido, en el considerando quince de la sentencia sobre el inmueble sin electricidad se lee

Aquí se "vendió" una casa que el vendedor levantó en terreno de propiedad del comprador Valdivia. Por consiguiente, no merece dudas a estos juzgadores que la obligación que contrajo el vendedor no está cumplida por mientras no se entregue al comprador el inmueble como un todo, tal cual reza el contrato -especie o cuerpo cierto- en estado de ser utilizado para el propósito que ambas partes entendieron al consentir, es decir, de vivienda; tan así, que "la cosa" fue instalada en sitio de dominio de valdivia.

La entrega imperfecta, entonces, correspondería a un incumplimiento de la obligación de entrega. En algún sentido, esto debería ser completamente obvio, pero no lo es. Y no lo es porque, como se ha visto, en ambos casos -las dos compraventas- se trata de anomalías cualitativas y, en el Código Civil, la disciplina de las anomalías cualitativas no es necesariamente la de la falta de entrega, sino más bien la de los vicios redhibitorios. Esto explica que en el considerando vigésimo primero de la sentencia de los rodillos de laminación, aparezca la defensa de la demandada consistente en alegar la prescripción de la acción indemnizatoria derivada de la existencia de vicios redhibitorios.

\section{Los efectos del incumplimiento}

¿Qué podemos leer en estas sentencias respecto a los efectos del incumplimiento del contrato?

Dos cosas. La primera de ellas refiere a la posibilidad de que las mismas circunstancias que configuran el supuesto de hecho de los remedios del acreedor propios del incumplimiento de la obligación de entrega, a su vez pueden configurar el supuesto de hecho de las acciones edilicias. La segunda enseñanza 
es que la acción indemnizatoria es autónoma respecto de la acción resolutoria o de cumplimiento forzado.

En ese orden las examinamos.

\subsection{Concursos ${ }^{21}$}

Podemos comenzar por la sentencia de los rodillos de laminación. Si nos detenemos en las defensas de la demandada nos encontramos con que, frente a la pretensión de indemnización de daños, alegó la prescripción de la acción asumiendo que se trataba de aquella propia de los vicios redhibitorios según los artículos 1861, 1866 y 1867. La Corte Suprema, sin embargo, entiende, en el considerando 21 de su sentencia, que esta defensa no procede, toda vez que la acción indemnizatoria deducida en autos correspondía a aquella "general de la responsabilidad contractual". ¿Cuál es esa acción? No puede ser otra que aquella propia de la obligación de entrega ex artículo 1824. Sin embargo, la demandada entendió que se trataba de la acción indemnizatoria emanada de la obligación de saneamiento por vicios redhibitorios.

Desgraciadamente la sentencia de la Corte Suprema se limita a despejar la defensa sin prestarle mayor atención. Aunque, al hacerlo, surgen las siguientes dos cuestiones. En primer lugar, podemos preguntarnos si resulta posible que las mismas circunstancias que configuran el supuesto de hecho de una acción redhibitoria constituyan, a la vez, el supuesto de hecho de la acción general de responsabilidad contractual. ${ }^{22} \mathrm{Si}$ la respuesta es afirmativa, nos encontraríamos frente a un concurso de acciones. Si es negativa, quiere decir que únicamente procede una de ellas. ${ }^{23}$ Por otra parte, asumiendo la existencia de un concurso, habrá todavía que preguntarse cómo ha de resolverse, y las opciones más aceptadas son dos. ${ }^{24}$ En primer lugar, podemos estimar que el acreedor puede elegir encausar su acción resarcitoria por cualquiera de las vías que le ofrece el derecho (concurso alternativo), esto es a través de la acción general de responsabilidad contractual o de la pretensión indemnizatoria del artículo 1861 CC. En segundo lugar, podemos considerar que el régimen de las acciones edilicias resulta especial respecto de la acción general de responsabilidad contractual y, por lo tanto, según el principio de especialidad dispuesto en el artículo 13 del Código Civil, el acreedor únicamente podría elegir disciplinar su pretensión por el régimen indemnizatorio sometido al régimen de las acciones edilicias.

\footnotetext{
${ }^{21}$ Sobre la idea de concurso puede consultarse DE LA MAZA (2011).

${ }^{22}$ Sobre el particular puede consultarse DE LA MAZA (2012).

${ }^{23}$ Así lo entendió la Corte en Cecinas La Preferida S.A. con sociedad Comercial Salinak Limitada (2005).

${ }^{24}$ Ver Caprile (2008) y Oviedo (2012).
} 
Se trata, como puede verse, de cuestiones extremadamente interesantes. Desafortunadamente, como expresamos, la Corte no profundiza en ellas, por eso nos contentamos, simplemente, con exponerlas. A continuación, nos ocupamos de una cuestión en la que la Corte sí se detiene en dos de las sentencias, la de los rodillos de laminación y el caso de la representación judicial: la autonomía de la acción de indemnización de perjuicios.

\subsection{La autonomía de la acción indemnizatoria}

Recordemos que en el caso de los rodillos de laminación el comprador realiza la entrega de la primera partida de un total de 1.500 toneladas y ante el cumplimiento defectuoso, la actora se limita a demandar directamente y en forma exclusiva la indemnización de daños. En el caso de la representación judicial, habiéndose ejecutado imperfectamente el mandato, el actor demanda la indemnización de daños. En ambos casos, el demandado alega como defensa el rechazo de la acción indemnizatoria por no haberse incoado conjuntamente, o con acción resolutoria o la de cumplimiento forzado, dado que aquélla sería accesoria o dependiente de cualquiera de éstas.

La autonomía de la pretensión indemnizatoria ha sido una discusión sostenida por largos años en el ámbito nacional. ${ }^{25}$ Podemos decir que, en una primera etapa -tendencialmente al menos- los tribunales superiores rechazaron dicha autonomía. Actualmente, la posición parece ser la contraria. Ambas sentencias lo muestran con elocuencia. Convendrá presentar los argumentos con que la Corte Suprema defiende la autonomía en cuestión.

En el caso de los rodillos la justifica en las reglas del pago y, en particular, lo que disponen sobre la forma en que debe hacerse el pago de las obligaciones de dar, entendiendo que la indemnización corresponde a lo debido por el contrato. En el considerando décimo de la sentencia se lee:

"DÉCIMO: Que, en todo caso, una demanda de daños y perjuicios en los términos que se han descrito, debe ser considerada como parte de lo que el vendedor debe en 'cumplimiento del contrato', de acuerdo con los términos del artículo 1489 del Código Civil. En efecto, conforme con el artículo 1591, 'el pago total de la deuda comprende el de los intereses e indemnizaciones que se deban'. Dado que en este juicio se pretenden indemnizaciones derivadas de un incumplimiento contractual, asociadas a una entrega imperfecta de la cosa vendida, debe entenderse que el deudor está ejerciendo una acción de cumplimiento contractual, para ser debidamente pagado por el deudor, aunque la acción esté reducida a

${ }^{25}$ LÓPEZ (2010). 
las indemnizaciones que el actor estima que la sociedad demandada le adeuda por incumplimiento del contrato".

En opinión de la Corte Suprema cuando el acreedor demanda la indemnización lo que hace es reclamar lo debido según la convención. De esta manera, se justifica el recurso al artículo $1591 \mathrm{del} \mathrm{CC}^{26}$. En otras palabras, el pago de la indemnización corresponde a lo que hubiese recibido el acreedor de haberse cumplido perfectamente el contrato. Aquí resultará conveniente recordar la regla de la previsibilidad del artículo 1558 que permite dibujar el objeto del contrato para el caso del incumplimiento expresado en una indemnización. La Corte, en el considerando décimo octavo de la sentencia, justifica la indemnización del lucro cesante en los siguientes términos:

“(...) La frustración de un negocio de esta naturaleza parecía perfectamente previsible, al tiempo de celebrar el contrato, para los efectos del artículo 1558 del Código Civil, pues, era natural que la empresa compradora quisiera revender el material de chatarra que estaba adquiriendo $(. . .)^{\prime \prime}$.

Consideremos ahora los argumentos a favor de la autonomía de la indemnización que pueden desprenderse de la sentencia acerca de la representación judicial.

La Corte Suprema anula la sentencia de segunda instancia que niega el carácter autónomo de la acción indemnizatoria, expresando lo que sigue:

"Que abordando esta última tesitura, y en concordancia con lo razonado en los motivos $1^{\circ}$ y $2^{\circ}$ de este sentencia de reemplazo, todo ello enmarcado en el rol orientador en la aplicación del derecho que le cabe a esta Corte Suprema, debe decirse que respecto de la indemnización de perjuicios pura y simple descartada por la sentencia recurrida, en atención a su carácter accesorio a la resolución o cumplimiento forzado del contrato conforme a los principios que integran el Código Civil, no se observan las particulares motivaciones que podrían inducir a privar a los afectados de dirigir las acciones en la forma y del modo como mejor se ajusten a sus intereses, desde el momento que el derecho civil otorga a las personas el principio de libre disposición de sus bienes y autonomía de la voluntad, todo lo cual lleva a reconocer las mayores prerrogativas al momento de someter las pretensiones al órgano jurisdiccional.

\footnotetext{
${ }^{26}$ Si debemos advertir que, tratándose en este caso de una obligación de dar no dineraria, también sirve como argumento el artículo 1590 del CC que prescribe para el evento que la cosa debida -refiere a especie o cuerpo cierto- sufra deterioros pendiente su entrega, obligando al deudor al pago de una indemnización por el cumplimiento imperfecto.
} 
Por lo anterior que esta Corte Suprema ha reconocido la independencia y autonomía de las acciones indemnizatorias, sean estas moratorias o perentorias, las que cualquiera sea la naturaleza del objeto de la prestación, pueden impetrarse en forma exclusiva, desde el momento que el legislador ha establecido su procedencia y la forma más usual de interposición, pero no ha prohibido la que en mejor forma repare integralmente el daño derivado del incumplimiento.

En efecto, la acción indemnizatoria no se encuentra ligada únicamente en sede contractual a la resolución o cumplimiento forzado de lo pactado, puede entonces cobrar identidad propia, como acción principal, aunque asociada a una de las variantes referidas resolución o cumplimiento forzado, como a ninguna de ellas, sin perjuicio que para ponderar esta pretensión resulta indispensable vincularla con el hecho en que se le hace descansar.

Entonces, ante la entidad independiente que la ley prevé en general, no existen razones para vincularla de manera determinante con cada una de aquellas acciones de resolución y cumplimiento, como tampoco para entenderla accesoria a las mismas.

Una razón fundamental surge para ello: tanto la teoría clásica, al considerar que la indemnización es la misma obligación cuyo cumplimiento se logra por medio de la justicia en naturaleza o por equivalencia, como por la teoría moderna que indica que la indemnización es una nueva obligación, lo que permite arribar a la conclusión que se trata de una obligación principal, nunca accesoria.

En sentido contrario, la interpretación exegética del artículo 1489 del Código Civil deriva de una lectura literal del mismo, se contrapone a la reparación integral del acreedor". ${ }^{27}$

${ }^{27}$ La Corte Suprema desarrollando el argumento de la reparación integral del acreedor expresa: "La indemnización permite colmar toda aquella parte del interés del acreedor insatisfecho por causa de incumplimiento, a la que los otros remedios no llegan o no pueden Ilegar, permitiendo así la realización del interés del acreedor en la prestación, afectada por el incumplimiento (Álvaro Vidal, La protección del comprador: Régimen de la Convención de Viena y su contraste con el Código Civil, Edic. Universitarias de Valparaíso, p. 198). En este mismo sentido, la profesora Patricia López Díaz, en su publicación sobre La indemnización compensatoria por incumplimiento de los contratos bilaterales como remedio autónomo en el Derecho Civil Chileno (Revista Chilena de Derecho Privado $\mathrm{N}^{\circ} 15$ ) sostiene: Un segundo enfoque para abordar dicha autonomía, consiste en sostener que el acreedor opta por demandar directamente la indemnización de los perjuicios derivados del incumplimiento del contrato, con el solo propósito de alcanzar la indemnización plena. El acreedor no podría obtener tal indemnización si demandara el cumplimiento forzado del contrato pues no existirían perjuicios por incumplimiento compensatorio o la resolución dado que en este caso la indemnización tendría el carácter de complementaria, de modo que no abarcaría todos los perjuicios derivados del incumplimiento. Continúa señalando que el ejercicio de la acción indemnizatoria implica la renuncia al 
Entonces, aquí la Corte Suprema justifica la autonomía, por un lado, en la libre disposición de los bienes y la autonomía de la voluntad, y, por otro, en el reconocimiento del derecho del acreedor a una reparación plena, sea demandando exclusivamente la indemnización o en forma complementaria, conjuntamente con la resolución o el cumplimiento forzado.

Pues bien, los vigorosos argumentos de la Corte Suprema en estas dos sentencias nos aconsejan zanjar la discusión acerca de la autonomía de la pretensión indemnizatoria. Sin embargo, no deberíamos aún abandonar del todo su funcionamiento. Si miramos con detenimiento los hechos sobre los que se pronuncian las sentencias advertimos ciertos matices que aconsejan una explicación.

En la sentencia de los rodillos de laminación, hay cumplimiento parcial -se entrega una de las partidas convenidas- y la demandante reclama exclusivamente la indemnización de daños por los rodillos defectuosos. Incluye en su pretensión el lucro cesante por la pérdida de las ganancias o utilidades del negocio frustrado con la empresa estadounidense -que concierne a la partida defectuosa enviada- y a aquéllas que habría obtenido por la celebración de negocios futuros. En otros términos, la actora demanda la indemnización del lucro cesante correspondiente al cumplimiento del contrato mediante la entrega perfecta de la totalidad de los rodillos. Y el Tribunal, reconociendo la autonomía de la acción, da lugar parcialmente a la indemnización del lucro cesante por la frustración del negocio con la empresa de Estados Unidos.

Partiendo de la autonomía de la indemnización de daños, debemos plantearnos la siguiente pregunta: ¿qué suerte corre la obligación de entrega pendiente de cumplimiento? Entendemos que cuando la demandante reclama sólo la indemnización de daños, ella no tiene interés en la conservación del negocio y en las entregas posteriores, aún no exigibles. En el caso, la obligación pendiente de cumplimiento se extingue, no por cumplimiento ni en especie ni en equivalente, sino que, como lo plantea algún autor por una especie de resolución parcial tácitamente acordada por las partes..$^{28}$ Esta respuesta explica

cumplimiento forzado o a la resolución del contrato. La indemnización se presenta entonces como un remedio autónomo, cualquiera sea la forma en que se ejecute la obligación; la única diferencia es el efecto inmediato derivado de la indemnización, toda vez que si se trata de un contrato de tracto sucesivo permite al acreedor seguir vinculado jurídicamente al deudor, una vez que éste le indemnice los perjuicios; y si el contrato es de ejecución instantánea o ejecución diferida conlleva la extinción del contrato, efecto que el acreedor ha asumido, y por consiguiente, le resulta irrelevante. Nótese que tal extinción del contrato no equivale a la resolución, dado que si así fuera la indemnización de perjuicios sería complementaria y no plena. Esta es, por tanto, la forma correcta de entender la autonomía indemnizatoria por incumplimiento de un contrato bilateral".

${ }^{28}$ Pizarro (2010), p. 311. 
el por qué la actora demanda la indemnización por todo el lucro cesante y por qué el Tribunal rechazó el lucro cesante, no por improcedente, sino por falta de prueba. ${ }^{29}$

En el caso de la representación judicial, si observamos con calma los hechos, aparece que el problema de la autonomía no se plantea, y no porque se trate del incumplimiento de una obligación de hacer como lo entiende la Corte Suprema, sino porque, en realidad, el actor no demanda la indemnización de perjuicios en forma exclusiva. Más bien demanda el cumplimiento forzado de la obligación de dar aquella suma de dinero no enterada por el abogado demandado al rendir su cuenta y, en complemento, la indemnización de los daños derivados de tal cumplimiento imperfecto.

Claramente, al tratarse de una obligación de dar una suma de dinero, el actor confunde ambas acciones derivadas del incumplimiento, la de cumplimiento y la indemnizatoria. Sin embargo, tal confusión pasa inadvertida, al punto que la Corte de Apelaciones rechaza la indemnización fundada en su carácter accesorio y la Corte Suprema, aunque fundamenta de manera contundente la aceptada autonomía, no advierte el error en que incurre el actor.

Ahora bien, no debemos entender que, con lo expresado respecto de esta última sentencia, estemos negando el carácter autónomo de la indemnización por el incumplimiento de obligaciones de dar. Nuestro ánimo consiste en mostrar que la cuestión que refiere a la autonomía de la acción resarcitoria demanda una mayor reflexión. Particularmente, exige prestar atención sobre los casos en que únicamente existe una apariencia de ejercicio autónomo de la acción indemnizatoria. Distintas hubieran sido las cosas si la obligación de rendir cuentas emanada del mandato hubiera comprendido la traslación de efectos no dinerarios al mandante. En ese caso se presenta con claridad un supuesto en el que el deudor pueda optar entre el cumplimiento forzado más la indemnización de daños y perjuicios y la sola indemnización. Los argumentos que nos suministra la Corte en las dos sentencias son suficientes para justificar esta conclusión.

\footnotetext{
${ }^{29}$ Esto no significa, sin embargo, asumir que cada vez que existe un cumplimiento imperfecto y se solicita autónomamente la indemnización sea necesario acudir a esta figura de la resolución parcial tácita. Bien puede ser que tengan lugar dos situaciones en que la solución va a ser distinta. La primera de ellas tiene lugar cuando el acreedor está interesado en reclamar la indemnización por los defectos del cumplimiento, el valor de la prestación aún pendiente de ejecución y otros daños subsecuentes, pagando la totalidad de precio. Aquí se inclina por una indemnización plena. En la segunda, el acreedor sólo demanda la indemnización de daños derivados del defecto, conservando el negocio respecto de las obligaciones pendientes. En estos dos casos, como en el de los rodillos de laminación, la acción indemnizatoria se ejercita autónomamente, no obstante, la respuesta sobre la suerte que corre la obligación aún pendiente de cumplimiento cambia: o se resuelve tácitamente, o se extingue por pago o por la indemnización.
} 


\section{Conclusión}

Pues bien, se trata de tres sentencias muy valiosas. Consideradas con suficiente atención nos enseñan acerca del contenido del contrato, de su incumplimiento y de la tutela del acreedor.

Respecto del contenido del contrato aprendemos acerca de la integración a través del principio general de la buena fe. Y una vez que le prestamos la atención requerida a este principio, descubrimos la importante noción de "propósito práctico" del contrato, es decir aquella finalidad procurada a través del contrato que éste protege. Por lo que toca al incumplimiento, la Corte nos enseña a tomarnos en serio la tipología del incumplimiento y a atender especialmente a un tipo más bien desatendido por nuestra doctrina: los cumplimientos imperfectos. Al considerar esta especie de incumplimientos y vincularlos con la tutela del acreedor vislumbramos la noción de concurso y los desafíos que presenta; desafíos que en el ámbito nacional se encuentran más bien pendientes. En fin, siempre respecto de la tutela del acreedor, la Corte Suprema termina de despejar la cuestión de la autonomía de la pretensión indemnizatoria. Sin embargo, los casos nos muestran que dicha autonomía debe ser considerada con atención pues presenta ciertas sutilezas que una aproximación apresurada encubre, enturbiando, de paso, nuestra adecuada comprensión del funcionamiento de los mecanismos de tutela del acreedor frente al incumplimiento.

Finalmente, creemos que al fallar como lo ha hecho, la Corte manifiesta un compromiso más reflexivo con el derecho de contratos $y$, particularmente, del incumplimiento y sus efectos, abandonando las interpretaciones innecesariamente exegéticas y abstractas de las disposiciones del Código Civil y ocupándose de las necesidades actuales del tráfico jurídico. Nociones como el "propósito práctico" del contrato, una acertada aproximación respecto de los cumplimientos imperfectos y atención a la adecuada tutela de la posición del acreedor constituyen, según nos muestra la Corte Suprema, herramientas que contribuyen a mantener el derecho de contratos del Código Civil atento a las necesidades de una economía 156 años alejada de aquella propia de los tiempos de su entrada en vigencia.

\section{Bibliografía CitADA}

Alcalde Silva, Jaime (2008): "El 'commodum repraesentationis' del artículo 1667 del 'Código Civil' de Chile", en: Revista de Derecho de la Pontificia Universidad Católica de Valparaíso (XXXI), pp. 37-161.

BARAONA GONZÁLEZ, Jorge (1998): El retraso en el cumplimiento de las obligaciones (Madrid, Dykinson).

Caprile Biermann, Bruno (2008): "Las acciones del comprador insatisfecho: el cúmulo actual (ley de protección al consumidor, vicios redhibitorios, error sustancial, resolución por incumplimiento) y la tendencia al deber de con- 
formidad en el derecho comparado", en: F. Mantilla Espinoza y C. Pizarro Wilson (coords.), Estudios de Derecho Privado en homenaje a Christian Larroumet (Santiago, Fundación Fernando Fueyo Laneri y Universidad del Rosario), pp. 561-602.

DE la MAZa Gazmuri, Iñigo (2011): "El concurso entre el error con trascendencia anulatoria y el incumplimiento resolutorio", en: ID. (ed.) Incumplimiento contractual: nuevas perspectivas, Cuadernos de Análisis Jurídicos, Colección de Derecho Privado VII (Santiago, U. Diego Portales), pp. 213-234.

de la Maza Gazmurı, Iñigo (2012): "El régimen de los cumplimientos defectuosos en la compraventa", en: Revista Chilena de Derecho (Vol. 39, № 3), pp. 629-663.

Dízz-PıCAzo, Luis (2008): Fundamentos de Derecho Civil patrimonial, Las relaciones obligatorias, (Cizúr Menor, Navarra Thomson Civitas), tomo II.

FueYo LANERI, Fernando (1958): "La ejecución de buena fe de los contratos como uno de los requisitos del pago", en: RDJ, tomo 55, pp. 95-113.

LÓPEZ DíAz, Patricia (2010): "La indemnización compensatoria por incumplimiento de los contratos bilaterales como remedio autónomo en el Derecho Civil Chileno", en: Revista Chilena de Derecho Privado (№ 15), pp. 65-113. Morales Moreno, Antonio Manuel (1983): "El propósito práctico y la idea de negocio jurídico en Federico de Castro", en: ADC (Vol. 36, № 4), pp. 15291546.

Oviedo AlBán, Jorge (2012): La garantía por vicios ocultos en la compraventa. Análisis de Derecho Privado chileno y colombiano a la luz de las nuevas tendencias del Derecho de contratos, Tesis para optar al grado de Doctor en Derecho, Universidad de los Andes.

PizARRo Wilson, Carlos (2010): "La responsabilidad contractual en el derecho chileno, función y autonomía", en: C. Pizarro Wilson y A. Vidal Olivares, Incumplimiento contractual, Resolución e Indemnización de daños (Bogotá, Editorial Universidad del Rosario), pp. 299-312.

Vidal Olivares, Álvaro (2010): “El incumplimiento de obligaciones con objeto fungible y los remedios del acreedor afectado. Una relectura de las disposiciones del Código civil sobre incumplimiento", en: C. Pizarro Wilson y A. Vidal Olivares, Incumplimiento contractual, Resolución e Indemnización de daños (Bogotá, Editorial Universidad del Rosario), pp. 137-208.

\section{JURISPRUDENCIA CITADA}

Cecinas La Preferida S.A. con sociedad Comercial Salinak Limitada (2005), Corte Suprema, 27 de julio de 2005 (Resolución de contrato. Indemnización de perjuicios procedente. Entrega de producto distinto al convenido. Compraventa). 
Glide Diversiones Limitada con Compañía de Inversiones y Desarrollo Sur S.A, (2008), Corte Suprema, 19 de mayo de 2008 (terminación de contrato de arrendamiento).

Zorin S.A. con Compañía Siderúrgica Huachipato S.A (2012), Corte Suprema, 31 de octubre de 2012 (compraventa, cumplimiento imperfecto de la obligación de entrega).

José Ampuero Asencio con Alfonso Castillo Hernández (2013), Corte Suprema, 28 de enero de 2013 (compraventa, cumplimiento imperfecto de la obligación de entrega).

José Valdivia Lucero con Same Madrid y Madrid y Compañía Limitada (2013):

Corte Suprema, 16 de abril de 2013 (contrato de mandato judicial, incumplimiento). 